\title{
Six Actionable Canons for Rationality in Strategy Practice
}

\author{
Roeland van Straten ${ }^{1,2}$ \\ Published online: 2 June 2020 \\ (C) The Author(s) 2020
}

\begin{abstract}
For strategists working in and for firms, acquiring knowledge about the business world is dependent on a rational process of collecting, organizing, and interpreting information. As such, these individuals are best conceived not as knowers, but as self-directing learners who are motivated to acquire, create, and apply new knowledge. To facilitate these processes, in this paper an axiomatic foundation for strategic thinking is established regarding the nature of the object of strategic thinking, the nature of strategic thinking, and the nature of knowledge. Next, four boundary references set by these axioms are used to establish a new conceptual frame of reference for strategic rationality. Interconnections between the boundary references are subsequently used to infer six canons for strategic rationality. It is concluded that strategic rationality may be found where all references overlap. Finally, to contribute towards greater rationality in strategic management practice, an actionable definition of strategic rationality is formulated that includes all references and canons.
\end{abstract}

Keywords Cash flows $\cdot$ Firms $\cdot$ Judgment $\cdot$ Rationality $\cdot$ Strategy

\section{Introduction}

Most issues in strategy are, in the final analysis, questions of judgment (Bennis and O'Toole 2005). In exceptional cases, strategic options are put forward by a single strategy maker but more commonly strategy making emanates from discussion and information exchanges between a group of people (Priem and Harrison 1994). Inevitably, strategists must make such judgments with incomplete data. The extent to which such data are incomplete will concomitantly impact on the likelihood the strategic decisions are optimal. Further, when the thinking itself is also messy, the possibility of sub-optimal or unwanted outcomes grows (Bennis and O'Toole 2005).

Roeland van Straten vanstraten@seyst.nl

1 University of Twente, Drienerlolaan 5, 7522 NB Enschede, The Netherlands

2 www.TheStrategyAcademy.com, Zeist, The Netherlands 
At the level of the firm, it is also important to remember that thinking is only strategic to the extent it is consequential for the outcomes, directions, survival, and competitive advantage of the firm (Johnson et al. 2003). For the purpose of this article, I adopt a narrow view, and only include thinking that is part of a formal process (Jarzabkowski et al. 2007). In doing so, it can be argued that the domain of strategy encompasses a firm's initial conditions, managerial cognition, and choice.

In line with this, Fowler (2003) concludes that strategic effectiveness requires that the strategist develops a holistic, but also dynamic view of a firm and its competitive environment. To this end the focus of the strategist should not be on the development of a static mental model of reality, but on the deployment of his or her cognitive capabilities for near real-time decision making, rooted in concepts such as renewal and resilience (Hamel and Välikangas 2003). Combining holisticism and dynamism would then require a form of integrated thinking which, according to Kachra and Schnietz (2008), can only result from a rational and ongoing learning process.

The foregoing means that, in strategic thinking, the firm and its environment constitute the object of thinking that is linked to the subject of thinking, being the individual strategist and his or her thinking skills and activities. Within this micro foundational conception of strategy, the rational strategist needs to develop the thinking and learning paradigms that enable attainment of the said holistic and dynamic perspective. This means that the strategist must learn to do his or her own empirical research and sensemaking and, although it is impossible to fully know the surrounding landscape or the true value of various combinations, the strategist must at least try to imagine what it is like. To this end, strategists must draw from available firm- or industry specific data and information or prior experience and use this to develop a mental model of a firm and its surrounding landscape. Once developed, the mental model could then be used to hypothesize about where to find the best opportunities for value creation for the firm, or it could be used in a process that is ultimately not just about decisions, but also about the legitimating of particular choices or practices (Vaara and Whittington 2012).

Clearly, this demand for cognitive flexibility makes the effective use of language paramount; language is what is used to create meaning, to frame action, and to prompt creativity (Dougherty 1993). Vaara and Lamberg (2016) even state the actual practice as enacted by strategists involves, to a large extent, the constructing of strategic narratives. In turn, these narratives are constituted by statements which, in a technical sense are codable units of verbal protocol (Maani and Maharaj 2004).

Ideally, the strategist is able to construct, articulate, and combine all narratives that tell the past, present, and future 'story' of a firm. Statements that relate to past and present would then echo what could be termed organizational identity in the strategic cognition perspective.

In the words of Narayanan et al. (2011), this construct serves as the basis for answering the question "Who are we as an organization?". This can be construed as a firm-specific version of the philosophical "Know Thyself". This identity is ultimately socially constructed and its continuity is maintained by conversations within an organization, which emphasizes that strategy exists in people's minds and in their theories about the world and their firm's place in it (Gavetti and Rivkin 2007; Narayanan et al. 2011). Unfortunately, developments in this domain pursuant of rationally constructing such narratives are still in their infancy, and overcoming decision making biases is not yet a well-distributed skill (Teece 2007).

Within the context of this micro foundational conception of strategy this article intends to contribute to the quest for greater rationality in strategic management by inferring a set of canons for strategic rationality in practice. The utility of this offering is found in the 
presumption that, for a strategist, acquiring true knowledge about the business world is dependent on a rational process of collecting, organizing, and interpreting information. As such, strategists are posed here not as knowers, but as self-directing learners who want to counter naive or false beliefs, and who are intrinsically motivated to acquire, create, and apply new knowledge (De Déa Roglio and Light 2009; Rousseau 2012).

\section{The Boundaries of Strategic Rationality}

Like the vast majority of research, this investigation did not occur in vacuo, but builds on prevailing paradigms and fundamental models (de Jong et al. 2015). In this instance, the research is built on a theoretical base of conceptual truths and axioms regarding the nature of a firm, the nature of strategic thinking, and the nature of knowledge.

Using an axiomatic foundation and logical inference follows from the argument that when the aim of a study is to discover guidelines for improving firm performance through increased rationality, one should reject a nomothetic view of causation. The fact that firms are dynamic and adaptive simply makes them ill-suited for this. Hence, an investigation that aims to improve strategic rationality in practice cannot rely on empirical investigation but must result from theoretical exploration. As a consequence, what is designed cannot claim scientific objectivity, and cannot qualify as a theory regarding firms or firm behavior. However, this shortcoming is not fatal because the investigation is aimed at formulating a theory about how a strategist should think about firms, not about how firms work, or how strategists actually think. The interest lies in a purposeful conceptualization of strategic rationality itself, not on the empirical content that is considered when it is applied.

Naturally, a conceptual model for strategic rationality that is based on a theoretical, normative research paradigm is merely an opinion unless it can claim authority in some way. This authority must come from justification that relies on a priori reasoning alone, or analytic philosophy. Resorting to philosophy in this way is not gratuitous because the theorizing that is part of this research relies necessarily and heavily on critical thinking and on the logical analysis of concepts and language. Based on these presumptions, the design of the proposed conceptual model for strategic rationality largely entailed a theoretical investigation into the possibility for and the, either inevitable or logical, boundaries of what is strategic rationality.

The next sections describe and substantiate the design of a new conceptual model for strategic rationality. This first design step entails the establishment of five fundamental axioms regarding the nature of the object of strategic thinking, the nature of strategic thinking, and the nature of knowledge (Table 1). All subsequent theorizing is based on these axioms. From these axioms, four boundary references for strategic rationality are inferred. As will be argued, the axioms and references reflect a justification approach to strategy practice.

The second design step entails the establishment of a novel conceptual frame of reference for strategic rationality (Fig. 1). This frame uses the boundary references identified in the previous step. The fundamental importance of this conceptual frame of reference can be illustrated by highlighting that it guides thinking about strategic rationality in four ways. Firstly, it reminds us that, in strategy practice, rationality combines thinking content with a thinking process. Secondly, the four boundaries present six canons for strategic rationality which correspond with the mutual interconnections of the boundaries (see dotted lines in Fig. 1). Thirdly, the interconnections between the three content-related boundaries (see dotted lines 1 through 3 in Fig. 1) further guide thinking by indicating it takes three assessment sub steps to 


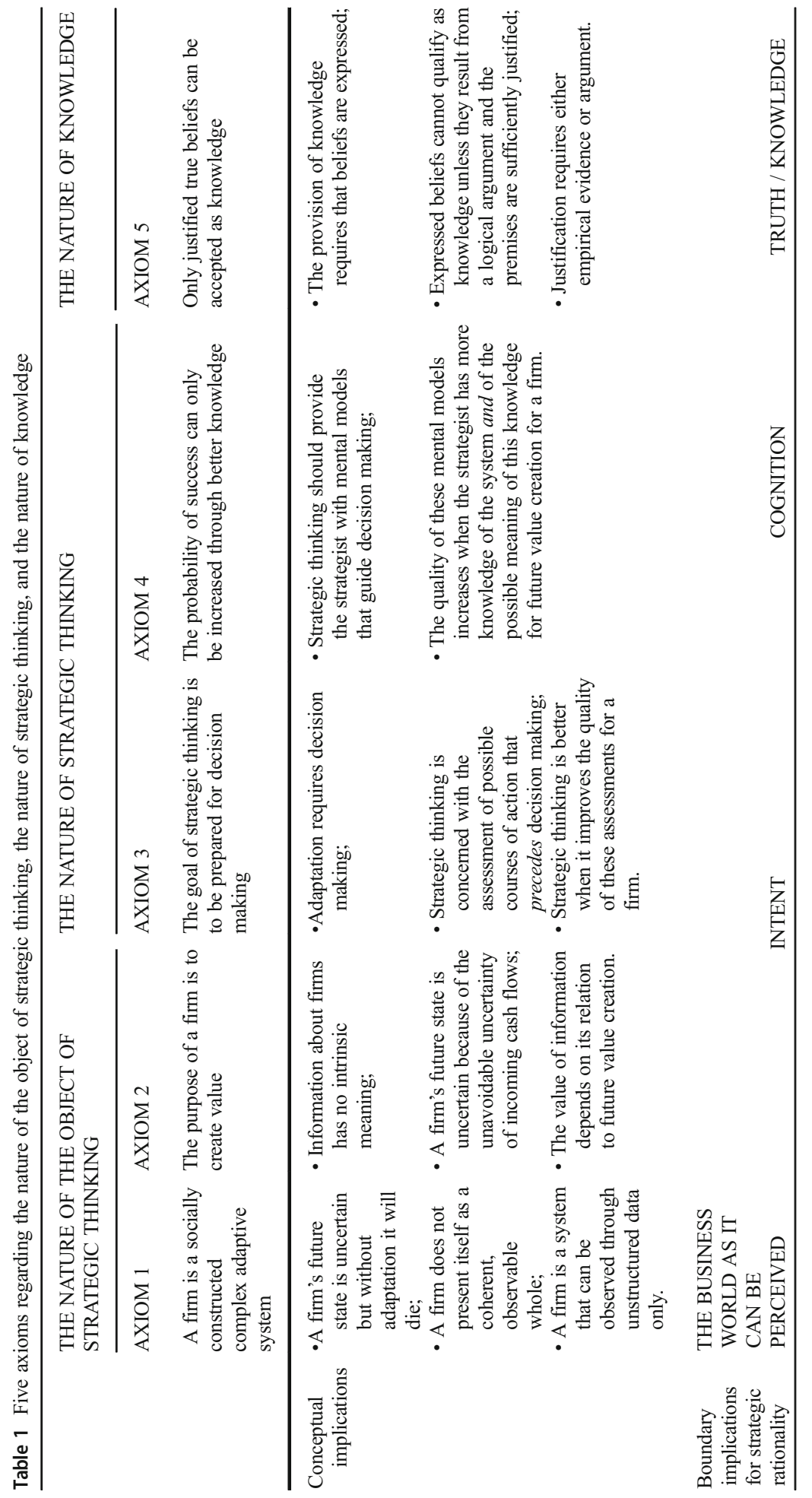




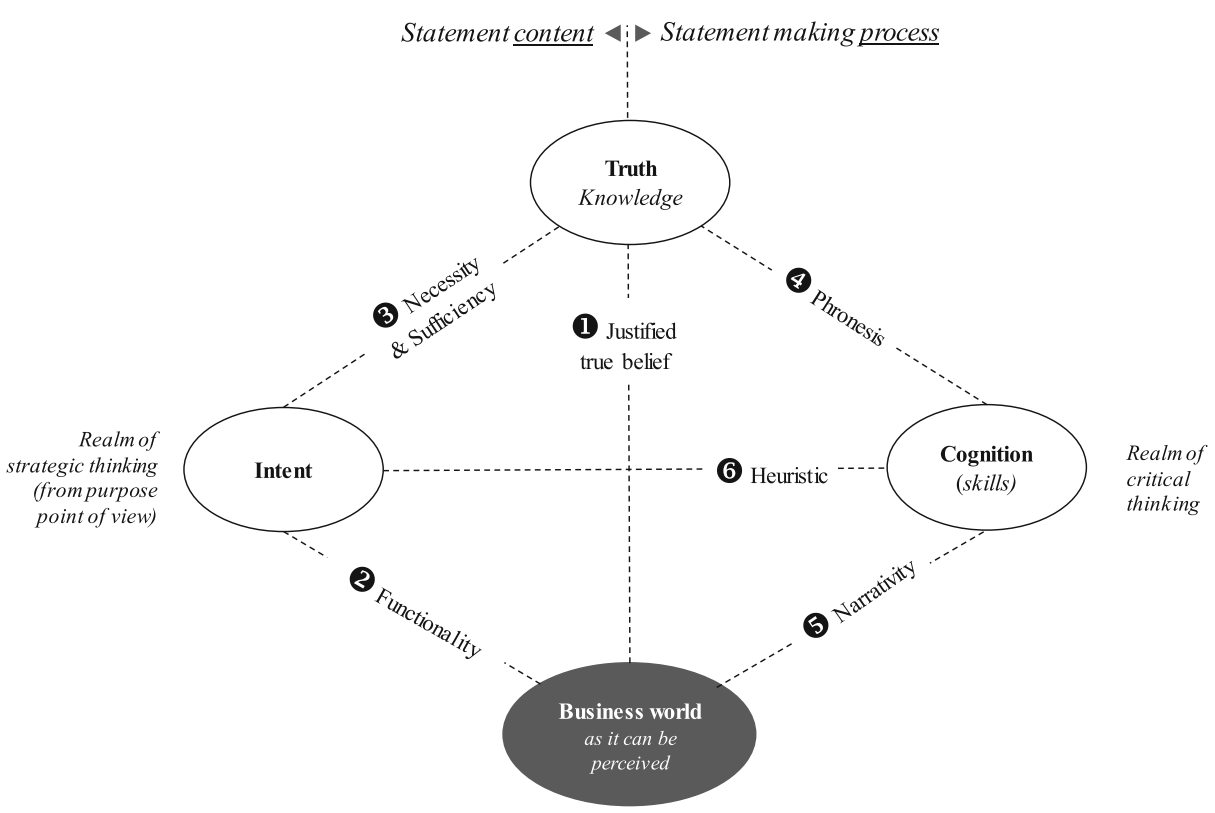

Fig. 1 A conceptual frame of reference for strategic rationality

establish the meaning of the knowledge that strategists need to generate. In lay terms, this assessment entails a more fundamental approach to the asking and answering of the 'So what?' questions that underlie much of the rigor versus relevance debate in strategy. Fourthly and finally, the frame of reference informs thinking about strategic rationality by offering the ingredients to formulate a holistic yet actionable definition of strategic rationality, which is also presented. This definition is inferred from the frame of reference and describes what a strategist should do to ensure strategic thinking is rational.

\section{Step 1: Establishing Axioms to Infer Boundaries for Strategic Rationality}

A total of five axioms are formulated. This includes two axioms regarding the nature of the object of strategic thinking, being the firm; and one regarding the nature of knowledge. This particular set of axioms is deemed necessary because when establishing knowledge about an aspect of reality, one must make specific assumptions about the nature of reality under investigation (i.e., ontology) and about the nature of knowledge (i.e., epistemology) (Sandberg 2005). Next, two fundamental assumptions are added regarding the nature of strategic thinking itself: one regarding the purpose of that thinking and one regarding the corresponding goal for an individual strategist's thinking. The axioms, several implications, and the conceptual boundaries they set for strategic rationality are presented in Table 1 and discussed below.

\section{Axiom 1: A Firm is a Socially Constructed Complex Adaptive System}

Unlike the real world, the 'business world' does not present itself as an observable whole but can only be experienced through unstructured data. Consequently, the firms and markets it 
consists of are both socially constructed phenomena (Gavetti et al. 2005). The nature of the decision making element in this constructed world - the firm - is, as the body of research amassed during the twentieth century shows, at the most abstract level seen as a complex, adaptive system (Bettis and Prahalad 1995). In this conceptualization, the purpose of the system to improve its behavior and thus the behavior of the system they comprise (Fowler 2003; Stacey 1996). In this case the system is characterized by a firm representing supply and markets representing demand. In dealing with the complexity of this system, there is the widely held belief that 'systems thinking' is a research paradigm that is superior to other approaches (Maani and Maharaj 2004). Adopting this paradigm means two levels of analysis are bridged: the functioning system and its components (Spender 1996). Secondly, it means the best representation of a firm based on the best possible data is nothing more than a depiction of the firm's state up to today. However, being an adaptive system, this state is not equal to the future state of the firm, and because there are no natural laws when it comes to its adaptation, it cannot fully inform the strategist of how the firm will develop. Consequently, this first axiom implies strategic rationality is bounded by the extent to which one can perceive the business world over time. This implies that the world that is relevant for strategic thinking is the business world as it can be perceived, being the world that is represented by the data that is or can be made available about firms and their environment.

\section{Axiom 2: The Purpose of a Firm is to Create Value}

Another difference between the real world and the world of firms is that the latter has an obvious purpose, which is to create value as an ongoing endeavor. It has long been accepted that the firm as a whole (and the individual businesses of the firm) has as a fundamental objective the achievement of superior and sustainable financial performance, measured in long-term profitability (Hax and Wilde 2001). Even more so, the business world only exists because of this purpose and, hence, it is the purpose itself that defines it. This dynamic aspect of a firm is also reflected in one of the tests for establishing if something qualifies as a complex adaptive system, being the second law of thermodynamics (Pascale 1999). This law states that the system must exhibit entropy and winding down over time. Or, as Pascale (1999, p.84) puts it, the system must be "vulnerable to death". It is a straightforward condition that is easily accepted as applying to firms as well. Of course, the process of maximizing value occurs within the context of meeting various social and environmental responsibilities, some of which are voluntary whereas others are mandated by governments (Kim et al. 2017; Piron and Fernandez 1995). A corollary of this is that maximizing value is not the sole purpose of a firm. However, all firms must recognize the reality that they will not survive unless they earn a rate of return at least equal to their cost of capital. As such, the value creation goal is a rational, working assumption that allows the strategist to identify how choices impact performance, and on that basis, to make decisions that contribute to that goal (Grant 2008).

Accepting the assumption that the purpose of a firm is to create value also means no data, information or knowledge has any intrinsic importance. Its purpose means rational strategic thinking is always contextual thinking, and this context demands that all thinking is ultimately aimed at value creation. This, in turn, also means that labeling something as strategic has no meaning when it is unclear how what is labeled relates to value creation. As a result, any conceptual model for strategic rationality should reflect the notion that knowledge of firms and markets is important, but ultimately only because of what its cash flow consequences mean for value creation (van Straten 2019). 
Another implication of this second axiom is that it reminds us of the need for absolute clarity in expression. Given that the strategist is seeking to render something that is complex into something which is more tractable, using terms that are ambiguous or hard to define would be counterproductive. They might be indicators of importance, but it would be much better to explicate why they are, by showing how they relate to the growth or decline of future cash flows. A casual and interchangeable use of words like value, profit, success, and return will only increase complexity. Even worse, it would prohibit rationality because if what is stated is expressed using ambiguous terms, it cannot be used effectively. Moreover, to safeguard that such fundamental premises, beliefs, and assumptions regarding value creation are shared by everyone involved, a firm's value creation purpose should be accepted as a dominant logic if rationality is to be a guiding principle. This logic then not only bounds procedures but also influences which behaviors and decisions should get rewarded (Wilson and Jarzabkowski 2004). Additionally, it determines what is viewed as relevant data, ensuring that the data which fall outside the value creating concept are sidelined or ignored (Bettis and Prahalad 1995).

\section{Axiom 3 The Goal of Strategic Thinking is to Be Prepared for Decision Making}

The previous two axioms conceptualize a firm as a purposeful, complex adaptive system. Therefore, they similarly imply that strategic thinking must be about a system that is complex and adaptive, and this thinking is goal-oriented whereby the goal relates to how it facilitates decisions among competing alternatives (Shepherd and Rudd 2014). Naturally, the best decisions are those that improve financial value creation the most. The strategist that denies that, either thinks money is available for free, or lacks a proper understanding of what it means in practice. Needless the say, the former is nonsensical and the latter is unfortunate - both need to be avoided. In establishing what is best, a firm's history always matters, but not in a deterministic way (Jarzabkowski et al. 2016). Therefore strategic thinking must rely heavily both on information gathering (Shepherd and Rudd 2014), as well as on reasoning, and in these activities norms should be followed for what would constitute right or wrong thinking. The dominant competitors for such a norm in this case would be utility maximization for the decision-making end-goal (maximal value creation) and logic for reasoning itself (Schurz 2011).

Following the above, the third axiom states that the goal of strategic thinking is being prepared for decision making rather than decision making itself. The difference between the two is found in the realization of two things. First of all, if decision making were the goal, there would also have to be alternatives to choose from. However, it is posited herein that alternative generation as such is not necessarily part of any rational view of actual strategic thinking. Reason will very likely inform such an activity, but the imagining of courses of action is only in part guided by objective, propositional knowledge that results from a proper use of reason. In fact, alternative generation is usually regarded as a creative process that draws on the ability of people to mentally imagine possibilities. As no model for rational thinking can replace or deliver creativity or personal experience, the step of alternative generation is not a logical part of any model that aims for strategic rationality. Secondly, if decision making were seen as the goal of strategic thinking this would mean all thinking that results in a decision could be strategic thinking, regardless of its quality. It would mean unstructured, delusional, nonsensical thinking could also qualify as strategic thinking when it results in a decision. Clearly such a conclusion is ludicrous hence why it is 
important to argue that the very term 'strategic thinking' should imply an intellectual effort that must comply with minimal standards of logic and obvious rationality for it to deserve the label.

When being prepared for decision making is accepted as the goal of strategic thinking it also rightfully emphasizes that in any conceptual model for strategic rationality both the content and process of the thinking that precedes decision making matter. It means effective strategic thinking thus requires an ongoing process of preparing for new decisions to pursue new courses of action (Mitchell et al. 2011). In turn, it implies the strategist sees its organizational context as a 'decision situation' at all times and that the focus should be on obtaining ever greater knowledge and understanding of the firm, the industry, and the market.

Combined, axioms 2 and 3 reflect an 'Intent' boundary reference for strategic rationality. It is the boundary reference that would make it a frame of reference for strategic rationality. It reminds us of the fact that strategic thinking is intentional thinking and, hence, so is strategic rationality. This boundary needs to be set to ensure that the content of strategic thinking is aligned with the purpose and goal of that thinking. If that were not the case, thinking could be logical but not purposeful, rendering it strategically irrational.

\section{Axiom 4: The Probability of Success Can Only Be Increased Through Better Knowledge}

Thinking is always done by individuals and generating knowledge for strategic decisionmaking demands cognitive efforts are deployed to develop mental models of reality that are complete and accurate in all significant respects. Such cognitive activities are crucial because they improve the outcomes that can be achieved, or the likelihood of achieving them, or the choices among alternatives (Augier and March 2007). In doing so, strategists should combine systems thinking as a paradigm with critical thinking as a disposition because their objective is not to find keys to guaranteed success, but to improve the odds through a thoughtful consideration of factors (Rosenzweig 2007). According to De Déa Roglio and Light (2009) the main purpose of critical thinking is to become aware of, and question, the tacit mental models that guide thinking, decisions, and actions. Being able to question implicit assumptions is an important contribution to the quality of strategic thinking as it is a way of becoming aware of false conclusions resulting in bad reasons to do something. It is what the gathering of knowledge in strategy is aimed at, at coming up with good reasons to do (or not do) or declare something. As such, anyone involved in strategic thinking should develop skills for constructing and analyzing arguments of other strategists, as well as their own. This is especially important in light of evidence suggesting that the major inadequacies of practical arguments are incompleteness and my-side bias (Smith 2003). That a strategist should learn to adopt a systems perspective in dealing with complexity is also supported by research. For instance Maani and Maharaj (2004) conclude that individuals who display the characteristics of systems thinking, even if they are oblivious to the fact, perform better on complex decision-making tasks. Sandberg and Tsoukas (2011, p. 340) refer to this as a logic that is representational and argue that "practitioners face a world of discrete objects whose pre-given features they represent through cognitive activity and, on the basis of those representations, undertake action".

If the aspects noted above are summarized in one conceptual boundary reference, it would be 'cognition', as this concept refers to the mental action or process of acquiring knowledge and understanding through both experience and the senses. For answers as to what this might mean for a conceptual model for strategic rationality it is best to defer to the scholarly fields of 
cognition and epistemology. Doing so would inform us that the most basic form of knowing constitutes the epistemological subject-object relation. In this relation, we find the strategist, as a thinking subject, on the one side, and the 'Business world as it can be perceived' (i.e., axiom $1)$, on the other.

Ultimately, any call for strategic rationality resolves down to strategists having the right skills for generating the type of knowledge that reduces the unavoidable uncertainty that typifies a firm. The ability to do this demands that the strategist becomes somewhat of an applied researcher as well as a strategic analytic philosopher. The first role is needed to go through an empirical phase, and the second for any further sensemaking and envisioning. As such, any conceptual model for strategic rationality should aid the strategist in the development of a broad, unbiased perspective and in thoughtfully working through to the conclusion that is most strongly supported (Smith 2003). It means strategic thinking requires a process of highlevel thinking that is essentially mental processing that uses one's knowledge and intellectual capacities to achieve certain goals (Smith 2003).

Naturally, because rationality implies the use and improvement of critical thinking skills, regardless of contents, any conceptual frame of reference for strategic rationality should also include a reference for the thinking process itself. After all, intentional thinking does not equal critical thinking, and truth is only concerned with the rules of thinking. This means truth and intent do not refer to thinking and learning as such. To this end, a 'cognition' boundary reference is needed. This addition also acknowledges the difference between knowing things and being wise. The former implies the existence of justified true beliefs that are supported by facts, whereas wisdom implies a person demonstrating sound and serene judgment in its use regarding the conduct of life (Kessler 2006). Wisdom therefore relates to the practical application of skills and knowledge, combined with a disposition to question all past knowledge. The skills needed to control this process are what constitute wisdom, not the outcome, because well-founded decisions do not guarantee a desired outcome, in the same way unfounded decisions might have great results; just ask any lottery winner. The fact that a lottery can be won, however, does not make buying a ticket a rational decision. In short, the strategist should hold reason, logic, and rhetoric in high esteem as well as the reality that, ultimately, one's cognitive capabilities both enable and limit the potential for strategic rationality.

\section{Axiom 5: Only Justified True Beliefs Can Be Accepted as Knowledge}

The previous axioms referred to the nature of the object of strategic thinking and what the subject of strategic thinking must do given the nature of the object. Stating that a strategist should work on gaining certain purposeful knowledge and understanding, however, is still not actionable unless it is clear what this knowledge would exactly entail, and what must be done to gain it. To explicate this further, three issues are discussed below: the type of knowledge that is sought after in strategic thinking; its theoretical demands; and what the gathering of knowledge requires from the strategist given these two aspects. As is argued, strategic knowledge revolves around justification, both when it comes to having it and gathering it.

First, it should be emphasized that all knowledge in management is propositional knowledge. By its very nature, propositional statements are expressed in declarative sentences or indicative propositions, and it is testable in terms of causal relationships. It is difficult to overstate the conceptual importance of this need for expression in strategy practice, particularly when one is reminded that, within the strategic thinking context, a firm is the expression 
of what we imagine it is, of our beliefs of it. Most people accept that for a belief to be knowledge it must be both true and justified, where justification is typically taken to be the normative quality whose presence makes (or at least marks) the difference between true belief and knowledge (Silva 2017). The concept of justified true belief states that to know that a given proposition is true, one must not only believe it is true, but also have justification for doing so. If that is the case, the proposition becomes accepted reality.

The second thing to consider in this respect is that the propositional knowledge relevant to strategy practice must be truth-conducive, meaning it makes it easier, possible or likely for something to exist or happen. This implies that when truth-conduciveness is combined with the justified true belief definition, a strategic thinking process must equal a belief-forming process that produces a high ratio of true to false beliefs. Hence, any frame of reference for strategic rationality should logically include a notion of 'truth' when it comes to the content of thinking.

Finally, although this fifth axiom does not relate to the business world or strategic thinking directly, it is the axiom that connects the content and process of strategic thinking. After all, justified true belief emphasizes both the need to express beliefs, and the need for justification of what is declared in that expression. The discourse that results from this statement generation then becomes a collection of pieces of text that has a functional and constructive effect on its context (Paroutis and Heracleous 2013).

\section{Step 2: Using the Boundary References to Form a Conceptual Frame of Reference for Strategic Rationality and Infer Canons}

After the axioms and corresponding boundaries are used to form the intellectual foundation for the development of a conceptual model for strategic rationality that can instruct thinking, two overall conceptual implications can be formulated. First, the axioms represent an approach to strategy that herein is termed a justification approach. This follows from a logical inference when cascading down the axioms. Such an exercise would tell us that strategy always concerns a firm, and that such a firm is a social construct that exists because of the statements that are made about it (axiom 1). Axiom 2 then informs us that, to prevent firm death, the construction of statements pertaining to value creation is needed. Axiom 3 subsequently tells us that this statement making requires a strategy actor to go through a thinking process, and the goal (axiom 4) of this process is to obtain the knowledge that is needed to construct the strategic narratives that form the core of all understanding pertaining to a firm, and which precede strategic decision making. Axiom 5 finally informs us that the statements that comprise these strategic narratives are propositional and must be justified. Hence, when it comes to strategic rationality there can be no truth or accepted reality without justification. Unfortunately, it is not always clear what is meant by justified and business remains a world without provable truths because it is impossible to replicate what happened in the past. This, however, does not mean that the strategist is left to guess, speculate or have unfounded opinions. Rather, it means that the notion of reasons provides the most adequate view of justification and this makes that justification become a matter of finding enough good reasons to make a decision whose outcome cannot be predicted. This is comparativism, the essence of which holds that justification comes in degrees; a strategist can have more or less justification to believe something (Silva 2017). In such a context, a rational view simply demands one seeks truth as best one can, because the more truth, the less uncertainty. And because the very seeking of justification 
in itself is already truth-conducive this argument holds even when soundness cannot be validated (Roche 2014). In other words, the very act of justification reduces uncertainty, and that is what rational strategists aim for.

The second implication is that once the boundary references are connected to form a model it becomes insightful to explore interconnections between the references, most notably to discern what they can provide in terms of criteria by which strategic rationality can be judged, both content wise and process wise. The four boundary references logically yield six interconnections and, when presented in the order as per Fig. 2, they reflect a content (left) and process (right) component, these interconnections can inform us of criteria by which both rational statement content and a rational statement generation process could be judged. First, the three content related canons are discussed. Next, it is illustrated how they, combined, offer an actionable framework for assessing the elusive 'So what?' question in strategic management. Subsequently the remaining canons are discussed, and an illustration is provided concerning what their combination could imply for strategic rationality.

\section{Canon 1: (Statements must Reflect) Justified True Beliefs}

Naturally, the first canon for strategic rationality should be that statements about an industry or firm aim for truth and greater knowledge and understanding. As was stated earlier, the 'justified true belief' definition of knowledge reflects not just strategic rationality as expressed through its contents (i.e., statements must reflect justified true beliefs), but also through its process (i.e., strategic rationality must be truth-conducive, following a process of justification).

\section{Canon 2: (Statements must Reflect) Functionality}

The second canon follows from the interconnection of the Business world as it can be perceived and the 'Intent' boundary references. The criterion this combination sets for rational strategic thinking is that generated statements must not simply reflect justified and true beliefs, but also be functional because, in strategy, statements must perform a task. Ultimately, they must present the strategist with reasons to do or not do something. The word 'functional' is chosen over the somewhat overlapping words 'applicability' and 'relevancy' because it is the instrumental building of argument that must be stressed here. A relevancy criterion would leave room for statements that intuitively inform the strategist in some way about a firm or industry, whereas it can still be completely unclear how they relate to value creation and, hence, how they could improve rationality when preparing for decision making. Nicolai and Seidl (2010) state that any kind of knowledge can be considered relevant to management practice to the extent that it makes some kind of difference to decision making, but that the term relevance as such does not imply a particular kind of difference. Much of what is being said about firms and industries sounds relevant, but not everything offers input for an actual, truthful decision-making process.

\section{Canon 3: (Statements must Reflect) Necessity and Sufficiency}

Connecting the 'Truth/Knowledge' and 'Intent' boundary references means strategic thinking must not only result in justified, true, and functional propositions, but also that this statement making must deliver beliefs that are individually necessary and collectively sufficient for strategic decision making. Here, 'necessary' means the arguments are regarded to be of 
defining importance for decision making because rationality ultimately entails weighing arguments to determine the most important arguments and, then, making a final judgment. 'Sufficient' means all such arguments are considered. The implicit assumption here is that when all important information is identified and evaluated, everything that could impact on the final decision is taken into account. Naturally, it is impossible to guarantee all important information in the above sense is included in strategic thinking but the conditional notion of necessity and sufficiency is nevertheless a logically inferred criterion for strategic thinking, and its use is certainly a powerful mental tool for increasing rationality (Smith 2003).

\section{Implications of the Content-Related Canons: How to Assess 'Meaning'}

At this point, three canons for the content of strategic rationality are identified and discussed that can be distilled from the conceptual frame of reference for strategic rationality. These three canons have prescriptive value, but not just in a conceptual sense. This becomes clear when they are viewed as guidelines for the assessment of the elusive meaningfulness of statements. Meaning is what strategists seek when the infamous "So what...?" question is posed. Asking for meaning is important for any strategist because it aligns the activity of thinking with the foreseen outcome of thinking and with the intent of that thinking. Somewhat surprisingly, when combined, the first three content-related canons provide a valuable instrumental framework for assessing meaning in strategic thinking. To understand this, it is important to recognize that meaningfulness in strategy is of a type that is discussed as part of the philosophy of language. In this field of study, theories of meaning are in fact synonymous with theories of truth. An important definition for meaning in this field is agreed upon by several important philosophers, including Aristotle, Augustine, and Aquinas. Effectively they state that meaning is a relationship between signs and the kinds of things these signs mean to express, intend or signify. This definition is useful in business thinking as it emphasizes the context-driven nature of meaning. Fig. 2 illustrates that inquiry into meaning can in fact be operationalized by asking a 'So what?' question that corresponds with an interconnection between the three contentrelated boundary references. This is suggestive of the idea that when all three questions are, or can be, answered satisfactorily in a strategic thinking process, this would indicate that propositional knowledge is aligned with the purpose of strategic thinking. All three questions can be asked to oneself to question and refine one's own beliefs or to others for the same reasons. They are discussed below.

\section{So What? What is the Claim of the Statement?}

This first question enquires into the declarative meaning of a statement, also known as the literal meaning or its denotation (see vertical line in Fig. 2). Similar questions are What is the message? What is your point? What exactly are you saying? This inquiry is aimed at establishing both the methodological soundness of the statement, and what is stated by it. As such, it logically reflects what is generally seen as the gateway standard for knowledge, which is clarity, both when it comes to syntax and semantics. Obviously, this demand for clarity rules out the use of any and all terms that are ambiguous and hard to define, including much management jargon, because they obscure real meaning. Even worse, lack of clarity introduces new complexity and uncertainty, which is the opposite of what knowledge and strategic thinking aim for. 


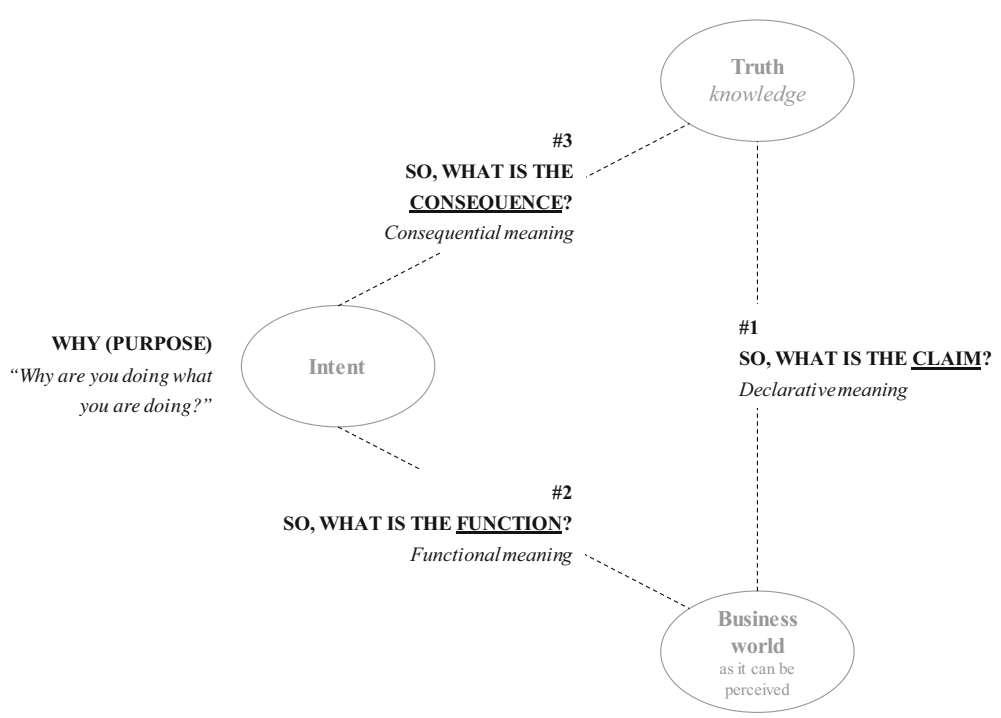

Fig. 2 A framework for assessing meaning

\section{So What? How is that Statement Functional for Strategic Thinking?}

This second question refers to the first specific strategic thinking-related 'Intent' boundary reference (see lower sloping line in Fig. 2). It enquires into the instrumental functional meaning of a statement, where functionality is related to the task that statements have in a strategic thinking process. By asking this question it is acknowledged that strategic thinking is intentional thinking, and that statements must therefore be governed and limited by the end-goal of being prepared for decision making (axiom 3).

\section{So What? Why Would that Statement Influence Decision-Making?}

Whereas the previous 'So what?' question demands that statements could function as a premise for a specific imaginable industry or firm, this final question asks what it can mean for value creation for an actual firm. It enquires into the consequential meaning of a statement (the upper sloping line in Fig. 2). Answering it requires being specific to the extent that if what is stated is of defining importance for a foreseeable decision, can be assessed. As decision making always takes place within a specific firm, this third question could also be "So what? Why would that also be important for this specific firm? " Answering it in a satisfactory way is possible only when the expressed belief and the assumed applicability are both sufficiently justified. When case studies are used as a source of knowledge, which is very common in strategy teaching, this becomes particularly problematic because the case study firm is clearly different in some way, rendering the identification of anomalies important to prevent flawed thinking. In such cases, propositional statements may still qualify as knowledge, but possibly only useful as theoretical knowledge of what might be important if it were applicable. For the decision-making process, however, it remains useless in a practical sense. It is still knowledge, with both declarative and functional meaning, but without consequential meaning. 
The foregoing suggests that to rationally assess thinking content, strategists would do well to always ask the three presented 'So what?' questions before passing any important, final judgments. And in doing so, it is easy to appreciate how an inquiry into declarative, functional and consequential meaning corresponds with the '...express, intend and signify' additions in the age-old definition of meaning as presented at the beginning of this section.

To continue, whereas the intent with which strategic thinking is undertaken and the nonsubstantial criterion that thinking content must be true and result in the making of justified statements relate to the 'why' and 'what' of strategic rationality, the 'how' relates to the process of improving the skills that are needed to act rationally in the process of strategic thinking. This aspect is conceptually covered by the cognition boundary reference. To render this concept more intelligible, the interconnections between this boundary reference and the 'Truth/Knowledge' and 'Business world as it can be perceived' boundary references can inform us about two further canons, which are discussed next.

\section{Canon 4: (Statement Generation must Reflect) Phronesis}

The fourth canon connects cognition with truth. This canon is best referred to as phronesis, being a type of wisdom that is concerned with how to act rationally in particular situations. Phronesis concerns the knowledge that defines the way we formulate our intentions and the course of action for achieving these intentions. Central to phronesis is practicing as we search continuously to exercise practical and prudent judgment when being purposeful in defining and pursuing particular objectives (Antonacopoulou 2010). Phronesis is the canon that refers to the 'how' of being truthful as an individual, and a strategist's attitude towards the task at hand. Within the context of strategic thinking, phronesis could be a form of questioning, reflective reasoning and a way of 'disciplined' thinking: an attitude of skepticism towards arguments and assumptions that is necessary when one aims for rationality (Antonacopoulou 2010).

\section{Canon 5: (Statement Generation must Reflect) Narrativity}

The need for narrativity represents the fifth canon in the conceptual frame of reference for strategic rationality. Barry and Elmes (1997) defined a narrative within the context of strategy as a thematic sequenced account that conveys meaning from implied author to implied reader. The use of narratives could be of particular importance given the need for sensemaking in strategy and for constituting "an overall sense of direction or purpose" (Fenton and Langley 2011, p. 1173), which is a valuable communicative aspect of any strategic thinking process. As such, it is often recognized that strategizing is in fact constituted by communicative processes (Brown and Thompson 2013). Naturally, a strategic discourse that results from the proposed use of narratives cannot be prosaic if it aims to be rational. To that end, it should be marked by judgments that are based on analytical reasoning and justification. Ultimately, the narratives should result in discursively negotiated and shared beliefs which refer to both the essence of what must be agreed upon, and the end-goal of value creation.

\section{Canon 6: (Statement Generation must Reflect) Heuristic}

Finally, given that the 'Intent' and 'Cognition' boundary references also interconnect, a sixth and final canon can be identified (see Fig. 2). This canon logically relates to the limitations brought forward by the strategist's cognitive skills and by the intent with which thinking 
efforts are undertaken. Because of the former, wise strategists should not only focus on the right way of thinking about a firm or industry, given their intent and desire for truth, but also on the best way to reach that thinking goal. Ideally, the thought process itself would be an exercise in getting better at that thinking as it could then serve as a heuristic. Good cognitive heuristics, including the use of structured narratives, are important thinking tools because they will reduce the number of variables included in the strategist's mental depiction of a firm. According to Maani and Maharaj (2004) there is evidence that supports heuristic competence i.e., the general competency to cope with complex systems. In that research, participants who display 'heuristic competence' are those that collect more information, do this more systematically, construct adequate goals, evaluate the effects of decisions, and generally behave in a systematic fashion.

\section{Implications of the Combined Process Canons: Rationality Requires Analytic Philosophizing}

Whereas the first three content-related canons indicate how the meaningfulness of statements can be identified or established, the process-related canons indicate who the strategist must be as an actor that is responsible for strategic thinking. To a large extent, these canons portray the need for a strategist that is first and foremost a reflective practitioner, much like an analytic philosopher. This conclusion is more obvious when the overlap between the process-related boundary references and canons, on the one hand, and the branches of analytic philosophy, on the other, are discerned and appreciated. These branches are epistemology (including logic), metaphysics and ethics. Of these branches, epistemology is logically covered by the 'justified true belief' canon, whereas metaphysics relates directly to the 'cognition' boundary reference. In turn, the 'phronesis' canon that connects the 'cognition' with the 'truth/knowledge' boundary reference could be seen as covering the ethical element because it demands fairness and open-mindedness.

The resulting combination of content- and process-related canons portrays strategic rationality as something that can only be demonstrated by a strategist who is somewhat of an analytic philosopher-researcher. The philosopher dimension in this typology reflects the analytic philosophical approach that is demanded by the inclusion of axioms 4 and 5; bounded by cognition and esteem for truth.

\section{Conclusions}

As Fig. 2 shows, all axioms are covered by the boundary references. Conceptually, this indicates that strategic rationality is possibly 'found' where all boundary references overlap. Put differently, when the boundary references and canons are combined, it may be concluded that a strategist's rationality is dependent on his or her ability to find the information that is required to construct the propositional statements that deliver the justified true beliefs that help form the discourse that improves the decision making that aims for value creation.

Figure 3 shows every boundary reference from Table 1 is included in this sentence, as is every canon from Fig. 1, albeit implicitly in some cases. For instance, the multiplicity of the justified true beliefs covers the 'necessity and sufficiency' of these statements, and the 'phronesis' canon is elementary to the discourse that improves strategic decision making. Of 


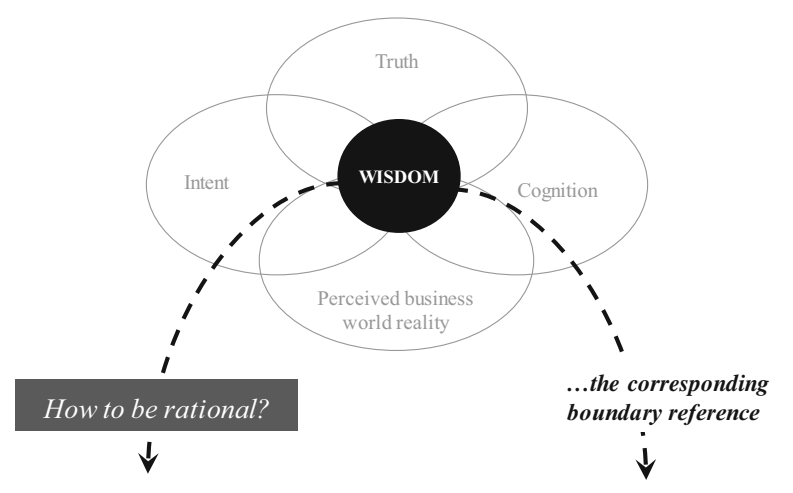

Find the information that is required to construct

the propositional statements that deliver the

iustified true beliefs that help form the

discourse that improves the

decision making that aims for

value creation
\} Business world reference

\} Cognition reference

\} Truth reference

\} Truth \& Cognition reference

Intent reference

Fig. 3 Strategic rationality may be found where all references overlap

course, this sentence does not prescribe what a practical model for strategic rationality looks like in practice. This conceptualization can only tell us that if the information is the right information used to form the right justified true beliefs, they will deliver the knowledge that is needed to form a sound strategic thinking process. Whether the information, statements, or decisions are right, however, can never be established. For one thing, there is no absolute norm for correctness in business. This is caused by the fact that value creation is a relative phenomenon. Besides that, it is beyond the bounds of anyone's cognitive capacities to examine all imaginable information and then discard what is not needed. Further, there will never be an identical control firm to compare the outcome of the decision to. Hence, it is not possible to conclude that a decision that was made at some point was the best possible decision at that time. It is simply unknowable. The consequence of this fundamental truth is that in practice, making the right decisions actually means making decisions in the right way. Of course, the second 'right' refers no longer to an outcome, but to the meeting of the canons of strategic rationality itself.

\section{Compliance with Ethical Standards}

Conflict of Interest The author states that there is no conflict of interest.

Open Access This article is licensed under a Creative Commons Attribution 4.0 International License, which permits use, sharing, adaptation, distribution and reproduction in any medium or format, as long as you give appropriate credit to the original author(s) and the source, provide a link to the Creative Commons licence, and indicate if changes were made. The images or other third party material in this article are included in the article's Creative Commons licence, unless indicated otherwise in a credit line to the material. If material is not included in the article's Creative Commons licence and your intended use is not permitted by statutory regulation or exceeds the permitted use, you will need to obtain permission directly from the copyright holder. To view a copy of this licence, visit http://creativecommons.org/licenses/by/4.0/. 


\section{References}

Antonacopoulou, E.P. 2010. Making the business school more 'critical': Reflexive critique based on phronesis as a foundation for impact. British Journal of Management 21: s6-s25.

Augier, M., and J.G. March. 2007. The pursuit of relevance in management education. California Management Review 49 (3): 129-146.

Barry, D., and M. Elmes. 1997. Strategy retold: Toward a narrative view of strategic discourse. The Academy of Management Review 22 (2): 429-452.

Bennis, W.G., and J. O'Toole. 2005. How business schools lost their way. Harvard Business Review 83 (5): $96-$ 104.

Bettis, R.A., and C.K. Prahalad. 1995. The dominant logic: Retrospective and extension. Strategic Management Journal 16 (1): 5-14.

Brown, A.D., and E.R. Thompson. 2013. A narrative approach to strategy-as-practice. Business History 55 (7): 1143-1167.

De Déa Roglio, K., and G. Light. 2009. Executive MBA programs: The development of the reflective executive. Academy of Management Learning \& Education 8 (2): 156-173.

de Jong, A., D.M. Higgins, and H. van Driel. 2015. Towards a new business history? Business History 57 (1): $5-$ 29.

Dougherty, D. 1993. [Book review] Beyond the hype: Rediscovering the essence of management. Administrative Science Quarterly 38 (4): 693-696.

Fenton, C., and A. Langley. 2011. Strategy as practice and the narrative turn. Organization Studies 32 (9): $1171-$ 1196.

Fowler, A. 2003. Systems modelling, simulation, and the dynamics of strategy. Journal of Business Research 56 (2): 135-144.

Gavetti, G., and J.W. Rivkin. 2007. On the origin of strategy: Action and cognition over time. Organization Science 18 (3): 420-439.

Gavetti, G., D.A. Levinthal, and J.W. Rivkin. 2005. Strategy making in novel and complex worlds: The power of analogy. Strategic Management Journal 26 (8): 691-712.

Grant, R. 2008. Why strategy teaching should be theory based. Journal of Management Inquiry 17 (4): $276-281$.

Hamel, G., and L. Välikangas. 2003. The quest for resilience. Harvard Business Review 81 (9): 52-63.

Hax, A., and D. Wilde. 2001. The delta model: Discovering new sources of profitability in a networked economy. European Management Journal 19 (4): 379-391.

Jarzabkowski, P., J. Balogun, and D. Seidl. 2007. Strategizing: The challenges of a practice perspective. Human Relations 60 (1): 5-27.

Jarzabkowski, P., S. Kaplan, D. Seidl, and R. Whittington. 2016. On the risk of studying practices in isolation: Linking what, who, and how in strategy research. Strategic Organization 14 (3): 248-259.

Johnson, G., L. Melin, and R. Whittington. 2003. Micro strategy and strategizing: Towards an activity-based view. Journal of Management Studies 40 (1): 3-22.

Kachra, A., and K. Schnietz. 2008. The capstone strategy course: What might real integration look like? Journal of Management Education 32 (4): 476-508.

Kessler, E. 2006. Organizational wisdom. Group \& Organization Management 31 (3): 296-299.

Kim, H., K. Park, and D. Ryu. 2017. Corporate environmental responsibility: A legal origins perspective. Journal of Business Ethics 140 (3): 381-402.

Maani, K.E., and V. Maharaj. 2004. Links between systems thinking and complex decision making. System Dynamics Review 20 (1): 21-48.

Mitchell, R.J., D.A. Shepherd, and M.P. Sharfman. 2011. Erratic strategic decisions: When and why managers are inconsistent in strategic decision making. Strategic Management Journal 32 (7): 683-704.

Narayanan, V.K., L.J. Zane, and B. Kemmerer. 2011. The cognitive perspective in strategy: An integrative review. Journal of Management 37 (1): 305-351.

Nicolai, A.T., and D. Seidl. 2010. That's relevant! Different forms of practical relevance in management science. Organization Studies 31 (9-10): 1257-1285.

Paroutis, S., and L. Heracleous. 2013. Discourse revisited: Dimensions and employment of first-order strategy discourse during institutional adoption. Strategic Management Journal 34 (8): 935-956.

Pascale, R.T. 1999. Surfing the edge of chaos: Treating organizations as complex adaptive systems provides powerful insights into the nature of strategic work. Sloan Management Review 40 (3): 83-94.

Piron, R., and L. Fernandez. 1995. Are fairness constraints on profit-seeking important? Journal of Economic Psychology 16 (1): 73-96.

Priem, R.L., and D.A. Harrison. 1994. Exploring strategic judgment: Methods for testing the assumptions of prescriptive contingency theories. Strategic Management Journal 15 (4): 311-324. 
Roche, W. 2014. On the truth-conduciveness of coherence. Erkenntnis: An International Journal of Scientific Philosophy 79 (3): 647-665.

Rosenzweig, P.M. 2007. The halo effect and the eight other business delusions that deceive managers. New York: Free Press.

Rousseau, D. M. 2012. Designing a better business school: Channelling Herbert Simon, addressing the critics, and developing actionable knowledge for professionalizing managers. Journal of Management Studies 49 (3): 600-618.

Sandberg, J. 2005. How do we justify knowledge produced within interpretive approaches? Organizational Research Methods 8 (1): 41-68.

Sandberg, J., and H. Tsoukas. 2011. Grasping the logic of practice: Theorizing through practical rationality. Academy of Management Review 36 (2): 338-360.

Schurz, G. 2011. Truth-conduciveness as the primary epistemic justification of normative systems of reasoning. Behavioral and Brain Sciences 34 (5): 266-267.

Shepherd, N.G., and J.M. Rudd. 2014. The influence of context on the strategic decision-making process: A review of the literature. International Journal of Management Reviews 16 (3): 340-364.

Silva, P. 2017. The composite nature of epistemic justification. Pacific Philosophical Quarterly 98 (1): 25-48.

Smith, G. 2003. Beyond critical thinking and decision making: Teaching business students how to think. Journal of Management Education 27 (1): 24-51.

Spender, J.C. 1996. Making knowledge the basis of a dynamic theory of the firm. Strategic Management Journal 17 (S2): 45-62.

Stacey, R.D. 1996. Strategic management and organisational dynamics. London: Pitman.

Teece, D.J. 2007. Explicating dynamic capabilities: The nature and microfoundations of (sustainable) enterprise performance. Strategic Management Journal 28 (13): 1319-1350.

Vaara, E., and J.A. Lamberg. 2016. Taking historical embeddedness seriously: Three historical approaches to advance strategy process and practice research. Academy of Management Review 41 (4): 633-657.

Vaara, E., and R. Whittington. 2012. Strategy-as-practice: Taking social practices seriously. The Academy of Management Annals 6 (1): 285-336.

Van Straten, R. 2019. Creating value in firms at different management levels. Foresight 21 (6): 695-707.

Wilson, D.C., and P. Jarzabkowski. 2004. Thinking and acting strategically: New challenges for interrogating strategy. European Management Review 1 (1): 14-20.

Publisher's Note Springer Nature remains neutral with regard to jurisdictional claims in published maps and institutional affiliations.

Roeland van Straten The author works as an independent strategy consultant, university lecturer and developer of post-MBA integration courses for the TheStrategyAcademy.com platform. Previously he held positions in corporate finance and private equity. His area of expertise is managing complex analysis and decision making processes in the field of business strategy, investment projects, and contract negotiations. In 2017, he received a doctorate degree for developing a unifying theory and method in the field of strategic management. 